\title{
TOTALITARISMO E DESUMANIZAÇÃO: o ser humano privado de direitos fundamentais em Hannah Arendt
}

\section{Totalitarianism and dehumanization: the human being deprived of their fundamental rights in Hannah Arendt's work}

\author{
Samylla de Sousa Pereira ${ }^{1}$
}

RESUMO: O presente trabalho propõe analisar como o totalitarismo desumanizou suas vítimas de forma arrasadora, deixando o homem desprovido da tutela de qualquer direito, representando assim uma ruptura no pensamento político ocidental, através da perspectiva da filósofa e pensadora política alemã Hannah Arendt. Um dos escritos mais importantes de Arendt, trata-se do livro Origens do Totalitarismo, lançado em 1951, no qual a mesma descreve os fatores que culminaram para o surgimento dos regimes totalitários no século XX. Todavia, neste estudo, será abordada a terceira e última parte da referida obra, na qual, a pensadora explana sua visão acerca do totalitarismo, sendo uma das primeiras intelectuais a discorrer sobre o tema que era tão recente no momento em que o livro foi publicado, tornando-se uma referência no mesmo. Hannah Arendt afirma que a forma totalitária de governo aniquilou a espontaneidade humana, privando o indivíduo de sua liberdade, impedindo-o de exercer a ação política, através de um partido que desumanizava suas vítimas, instaurando o terror e exercendo o domínio total sobre indivíduo, deixando-o um ser completamente apático. Porém, antes de adentrar no pensamento de Arendt, será realizado um breve apanhado sobre a história dos direitos humanos.

Palavras-chave: Totalitarismo. Desumanização. Direitos Fundamentais.

ABSTRACT: The present paper proposes to analyze how Totalitarism dehumanized its victims in a devastating way, leaving men deprived of the protection of any rights, thus representing a rupture in Western political thought, through the perspective of the German philosopher and political thinker Hannah Arendt. One of Arendt's most important writings, The Origins of Totalitarism, published in 1951, describes the factors that climaxed on the emergence of the totalitarian regimes in the XX century. However, in this study we will approach the third and lat part of the referred book, in which the thinker explains her conception of Totalitarism, being one of the first intellectuals to elaborate on such a recently emerged topic, what made her a reference on the subject. Hannah Arendt states that the totalitarian way of governing annihilated human spontaneity, dispossessing the individual from their freedom, forbidding them of carrying on their political action, through a party which

\footnotetext{
${ }^{1}$ Bacharel em Direito pela Universidade Estadual do Piauí - UESPI. Graduanda do curso de Licenciatura Plena em História, pela Universidade Estadual do Piauí - UESPI. E-mail: samylladesousa@gmail.com
} 
dehumanized its victims, established terror and exercising total dominium over the individuals, turning them into totally apathic beings. However, before diving into Arendt's thought we will present a brief summary of the history of Human Rights.

KEY-WORDS: Totalitarianism. Dehumanization. Fundamental Rights.

\section{CONSIDERAÇÕES INICIAIS}

Hannah Arendt viveu no período entre guerras. Por ser de origem judia, a pensadora precisou fugir da perseguição ocorrida durante Alemanha nazista, encontrando-se por muitos anos como apátrida e vivendo em alguns países nesta situação, como a França, lugar onde chegou a ser apreendida em um campo de concentração. Arendt conseguiu fugir do campo durante a invasão dos alemães no país, indo para Nova York, e dez anos depois de residir nos Estados Unidos, a filósofa conseguiu a cidadania americana

Para a filósofa, o totalitarismo causou a coisificação do homem, arrancandoIhe brutalmente sua liberdade, fazendo assim com que o mesmo se transformasse em algo descartável para o Estado, que não garantiu seus direitos fundamentais ou o respeito a sua dignidade humana, por este trazer consigo a humanidade, algo extremamente perigoso para o totalitarismo. Houve, desse modo, a inexistência de direitos que foram garantidos ao longo da história. Por ser uma ruptura da tradição política ocidental, o totalitarismo era um fenômeno completamente novo. Vendo-se diante de tal ruptura, a filósofa alemã, observou o ineditismo que este sistema trouxe ao mundo, sendo uma das primeiras pensadoras a debruçar-se sobre seu estudo.

\section{CONCEITO}

Frequentemente, direitos humanos, direitos fundamentais, e direitos do homem, são referidos como se possuíssem o mesmo conceito, porém, é um equívoco pensar que estes possuem o mesmo significado. Direitos do homem seriam aqueles valores ainda não positivados em um texto escrito. Os Direitos humanos, sendo direitos norteadores, são aqueles consagrados e positivados em declarações e tratados internacionais, dispondo de caráter universal para todos os homens. Por outro lado, direitos fundamentais, são um grupo de direitos positivados no texto constitucional de um Estado, assegurando a dignidade humana a todos os 
indivíduos. O renomado constitucionalista José Afonso da Silva, ao definir o que seriam os direitos fundamentais, ensina que:

Direitos fundamentais [...] além de referir-se a princípios que resumem a concepção do mundo e informam a ideologia política de cada ordenamento jurídico, é reservada para designar, no nível do direito positivo, aquelas prerrogativas e instituições que ele concretiza em garantias de uma convivência digna, livre e igual de todas as pessoas [...] Fundamentais do homem no sentido de que a todos, por igual, devem ser, não apenas formalmente reconhecidos, mas concreta e materialmente efetivados, do homem não como macho da espécie, mas no sentido de pessoa humana. (SILVA, 2007, p. 178).

Para o jurista Ingo Wolfgang Sarlet:

Praticamente não há mais Estado que não tenha aderido a algum dos principais pactos internacionais (ainda que regionais) sobre direitos humanos ou que não tenha reconhecido ao menos um núcleo de direitos fundamentais no âmbito de suas Constituições. (SARLET, 2010, p. 21).

Pode-se dizer que os direitos fundamentais, são direitos que tem por obrigação a proteção da pessoa humana, defendendo-a em face do Estado, limitando o poder e a ação deste, em prol do bem-estar de seus cidadãos.

\section{CONSIDERAÇÕES SOBRE OS DIREITOS FUNDAMENTAIS}

Os direitos fundamentais foram construídos pelo homem ao longo do tempo, à medida em que estes refletiam as necessidades, anseios e pretensões de uma determinada época, e em uma determinada sociedade. Pode- se dizer, que eles remontam desde o cristianismo em sua forma primitiva, visto que na tradição judaico-cristã, que tanto influenciou a cultura ocidental, o homem fora criado a imagem e semelhança de Deus, devendo assim, ser tratado com dignidade por trazer consigo o criador. São, portanto, direitos que tem por obrigação a proteção da pessoa humana, defendendo-a em face do Estado, limitando o poder e a ação deste, em prol do bem-estar de seus cidadãos.

Tempos depois, durante o século XVIII, o calor do movimento iluminista exaltava a racionalidade humana em contraponto ao Antigo Regime e ao dogmatismo religioso, visto que a Igreja Católica há muito havia se transformando 
em uma instituição, afastando-se da concepção inicial do cristianismo baseada na igualdade de todos os homens. A Igreja agora fundamentava a monarquia absolutista através da ideologia do direito divino, na qual o rei era o escolhido de Deus para governar. Assim, neste contexto de descontentamento por grande parte da população (principalmente a burguesia), revoluções foram travadas contra a opressão exercida pelo monarca absoluto, em busca de ideais como igualdade, liberdade política e de pensamento, direitos até então tidos como inconcebíveis. Para Trindade:

\begin{abstract}
A teoria do direito natural inverte, pois, completamente, a 'pirâmide feudal'. Em lugar de relações verticais (hierarquizadas) instaurar-seão relações horizontais (comunidade nascida do contrato social). Deixará de haver ordens correspondendo a funções separadas e desiguais em direitos, não haverá senão homens livres e iguais, quer dizer, cidadãos. Deixará de haver rei no cume da pirâmide para governar os homens, mas a expressão da sua vontade, isto é, a lei. A burguesia, e particularmente, a burguesia francesa, finalmente encontrava um poderoso arsenal ideológico para refutar a visão social de mundo do passado (TRINDADE, 2002, p.38).
\end{abstract}

Segundo Paulo Mendes de Tarso "a evolução histórica dos direitos fundamentais tem conexão direta com os documentos que a positivaram" (MENDES DE SOUZA, 2009, pag. 117). A ideia de direitos fundamentais, só pode ser concebida após o nascimento do Estado Democrático Direito a partir das revoluções da segunda metade do século XVIII, originando as declarações de direitos escritas, que tinham em seu conteúdo, os interesses da população, indo contra a vontade do rei absolutista.

Por conseguinte, tais direitos precisavam afirmar-se nos planos jurídico e político para que através da sua normatização, de forma solene em um documento escrito, consolidarem-se na sociedade. Portanto, para que houvesse a sua expansão e efetivação, tornou-se imprescindível que houvesse uma transição, ocorrida entre um plano meramente simbólico (como o divino) para o mundo real e politizado. Sobre isto, a historiadora Lynn Hunt, em A Invenção dos Direitos Humanos, fala que:

Entretanto, nem o caráter natural, a igualdade e a universalidade são suficientes. Os direitos humanos só se tornam significativos quando ganham conteúdo político. Não são os direitos de humanos num estado de natureza: são os direitos de humanos em sociedade. Não 
são apenas direitos humanos em oposição aos direitos divinos, ou direitos humanos em oposição aos direitos animais: são os direitos de humanos vis-à-vis uns aos outros. São, portanto, direitos garantidos no mundo político secular (mesmo que sejam chamados "sagrados"), e são direitos que requerem uma participação ativa daqueles que os detêm. (HUNT, 2009, p. 11).

A insatisfação política existente entre os burgueses fez surgir, dentre os movimentos mais conhecidos, a Revolução Americana, de 1776, contra os abusos da colônia inglesa, e a Revolução Francesa, de 1789, em resposta ao poder ilimitado do monarca soberano. A partir destas revoluções, nasceu um novo modo de pensar a relação que envolvia os homens e o Estado. Para Norberto Bobbio, em seu clássico livro A Era dos Direitos, as mudanças ocorridas nas revoluções do século XVIII mudaram drasticamente o pensamento político vigente, considerando que:

O ponto de vista tradicional tinha por efeito a atribuição aos indivíduos não de direitos, mas sobretudo de obrigações, a começar pela obrigação da obediência às leis, isto é, às ordens do soberano. Os códigos morais e jurídicos foram, ao longo dos séculos, desde os Dez Mandamentos até as Doze Tábuas, conjuntos de regras imperativas que estabeleceram obrigações para os indivíduos, não direitos. Ao contrário, observemos mais uma vez os dois primeiros artigos da Declaração. Primeiro, há a afirmação de que os indivíduos têm direitos; depois, a de que o governo, precisamente em consequência desses direitos, obriga-se a garanti-los. A relação tradicional entre direitos dos governantes e obrigações dos súditos é invertida completamente. (BOBBIO, 2004, p. 94).

Entre as declarações escritas durante o período revolucionário ocorrido no fim do século XVIII, pode-se destacar a Declaração dos Direitos do Homem e do Cidadão, consagrada na França, no ano de 1789. Considerada como inspiração para as declarações que vieram posteriormente, sendo, de acordo com Manoel Gonçalves Ferreira Filho "por um século e meio modelo por excelência das declarações, e ainda hoje merecer o respeito e a reverência dos que se preocupam com a liberdade e os direitos do homem (FERREIRA FILHO, 2009, p. 19) ". Esta declaração francesa, editou em seus artigos, aqueles ideais almejados pela população, tais como a liberdade e a igualdade dos indivíduos, possuindo também, um caráter abstrato, pois tinha como destinatário, o homem em geral. Segundo os dois primeiros artigos da Declaração dos Direitos do Homem e do Cidadão: 
Artigo 1-. Os homens nascem e são livres e iguais em direitos. As distinções sociais só podem fundar-se na utilidade comum.

Artigo $2^{ }$- A finalidade de toda associação política é a conservação dos direitos naturais e imprescritíveis do homem. Esses direitos são a liberdade, a propriedade a segurança e a resistência à opressão.

Assim, as declarações de direitos, provenientes das revoluções burguesas do século XVIII, foram fruto de um pensamento em comum, que tinha como fonte principal o iluminismo europeu, com filósofos como John Locke, Montesquieu e Jean-Jacques Rousseau, este último, autor do livro O Contrato Social, obra em que fala sobre o pacto feito entre os homens para o surgimento da sociedade civil e do Estado. Em uma passagem de o contrato social, Rousseau fala da importância das leis para a criação da sociedade civil, na qual diz que "as leis não são, propriamente, mais do que condições da associação civil [...]. Só àqueles que se associam cabe regulamentar as condições da sociedade (ROUSSEAU, 1978, p. 55)".

Portanto, com a edição das declarações, surgiu a concepção moderna de Estado, havendo, uma mudança, envolvendo o Estado e o indivíduo, considerando que este último não mais ficou inerte nas mãos do governante. Desta maneira, a ideia de Estado Democrático de Direito, deu-se com a consagração dos direitos fundamentais em declarações dotadas de caráter universal, que logo em seguida foram positivados através da Constituição de cada país. Contudo, a constante transformação dos direitos inerentes a todos os seres humanos, encontrou o seu ápice na Declaração Universal dos Direitos Humanos, a qual foi promulgada pela Assembleia Geral da Organização das Nações Unidas - ONU, em 1948, enquanto o mundo ainda se recuperava atônito dos horrores causados durante Segunda Guerra Mundial (1939-1945), que ficou marcada pelo extermínio em massa, o qual se deu em proporções nunca vistas anteriormente.

$\mathrm{Na}$ Declaração Universal de 1948 estão contidos os clássicos direitos relativos à liberdade, à igualdade, à vida, e à crença, visando garantir a todos os seres humanos não somente os direitos já consolidados ao longo do tempo, como também outros direitos nascidos no pós-guerra, como o direito de asilo político e ao de ter uma nacionalidade, conforme pode-se notar nos três primeiros artigos da declaração: 
Artigo 1.

Todos os seres humanos nascem livres e iguais em dignidade e direitos. São dotados de razão e consciência e devem agir em relação uns aos outros com espírito de fraternidade.

\section{Artigo 2.}

1. Todo ser humano tem capacidade para gozar os direitos e as liberdades estabelecidos nesta Declaração, sem distinção de qualquer espécie, seja de raça, cor, sexo, idioma, religião, opinião política ou de outra natureza, origem nacional ou social, riqueza, nascimento, ou qualquer outra condição.

2. Não será também feita nenhuma distinção fundada na condição política, jurídica ou internacional do país ou território a que pertença uma pessoa, quer se trate de um território independente, sob tutela, sem governo próprio, quer sujeito a qualquer outra limitação de soberania.

Artigo 3.

Todo ser humano tem direito à vida, à liberdade e à segurança pessoal.

Com a Declaração Universal dos Direitos do Homem e do Cidadão, o reconhecimento de tais direitos passou, segundo Norberto Bobbio "da esfera nacional para a internacional, evolvendo - pela primeira vez na história - todos os povos (BOBBIO, 2004, p. 46)". Assim, esta declaração, retomou os ideais igualitários e libertários da revolução francesa (liberte, égalité e fraternité), porém, não mais em um sentido de resguardar o indivíduo de um Estado específico, mas sim os cidadãos do mundo inteiro, dado o seu caráter internacionalista.

\section{O TOTALITARISMO E A DESUMANIZAÇÃO DO HOMEM}

De acordo com a filósofa alemã Hannah Arendt, o totalitarismo trata-se de algo inteiramente novo, visto que este regime causou uma ruptura com toda a tradição do pensamento político ocidental conhecido, no qual "poderíamos dizer que ele destruiu à própria alternativa sobre a qual se baseiam, na filosofia política, todas as definições da essência dos governos, isto é, alternativa entre o governo legal e o ilegal, entre o poder arbitrário e o poder legítimo (ARENDT, 2012, p. 613)". Assim, o totalitarismo, aniquilou de maneira cruel, através, do domínio total, do terror e da ideologia, toda a humanidade que possa estar presente no homem, destruindo "todos os vestígios do que comumente chamamos de dignidade humana (ARENDT, 
2012, p. 608)", procurando transformar a natureza do indivíduo. Para o jurista brasileiro Celso Lafer:

Trata-se, em verdade, de um regime que não se confunde com a tirania, nem com o despotismo, nem com as diversas modalidades de autoritarismo, pois se esforça por eliminar, de maneira inédita, a própria espontaneidade - a mais genérica e elementar manifestação da liberdade humana. Gera, para alcançar este objetivo, o isolamento destrutivo da possibilidade de uma vida pública - que requer a ação conjunta com outros homens - e a desolação, que impede a vida privada. (LAFER, 1988, p. 117).

Justamente por tratar-se de uma ruptura, Arendt diz que o totalitarismo diverge de outros regimes como a ditadura por exemplo, posto que o terror desta última "difere do terror totalitário, por ameaçar apenas adversários autênticos, que realmente queriam e planejavam derrubar o sistema vigente, mas não cidadãos inofensivos e carentes de opiniões políticas (ARENDT, 2012, p. 452)", já que para o totalitarismo era preciso combater as pessoas chamadas de inimigos objetivos, tidas como perigosas "para o Estado, porque portadoras de tendências, como alguém pode ser portador de uma doença (LAFER, 1988, p. 100)".

Era a polícia secreta totalitária, a encarregada de lidar com os inimigos objetivos do Estado. Esta organização "assume a posição de assegurar, através do terror, a permanente transformação da ficção ideológica em realidade (LAFER, 1988, p. 100)". De acordo com Hannah Arendt, "o dever da polícia totalitária não é descobrir crimes, mas estar disponível quando o governo decide aprisionar ou liquidar certa categoria da população (ARENDT, 2012, p. 566)", visto que polícia não tem como finalidade a função de "prevenir ou descobrir crimes, como o seria o de uma polícia normal no Estado de Direito, ou então fiscalizar, desvendar e prender os suspeitos de hostilidades em relação ao regime, como é o caso da polícia em regimes despótico-autoritários e tirânicos (Lafer, 1988, p. 101)", pois todos são para a polícia totalitária, suspeitos em potencial, já sendo considerados culpados durante a apreensão.

As leis para o totalitarismo podem ser tidas como o seu próprio movimento de expansão, pois "todas as leis se tornam leis de movimento (AREDNT, 2012. p. 615)", sendo elas leis da natureza para os nazistas alemães, visto a crença deste na superioridade da raça ariana sobre as demais, ou leis da história para os soviéticos, lembrando a luta de classes idealizada por Karl Marx. 
Por exigir uma lealdade incondicional de todos os indivíduos sob seu poder, deixando-os sem o senso crítico de questionar o Estado em que vivem, "as pessoas encontram dificuldade para elaborar convicções políticas à medida que são deixadas no isolamento e incapacitadas para refletir verdadeiramente sobre a situação (FRY, 2010 , p. 36)". Desta forma, a propaganda tem grande importância para o totalitarismo sustentar as ficções criadas pelo governo dominador, posto que se deve levar em consideração que esta tem "capacidade de isolar as massas do mundo real (ARENDT, 2012, p. 488)", concebendo as histórias mais absurdas possíveis.

Como um instrumento de opressão e de domínio absoluto dos indivíduos pelo governo "a propaganda reforça a ideologia e nem sequer importa se os membros acreditam na propaganda, contanto que a capacidade de distinguir a diferença entre verdade e falsidade seja abolida da sociedade (FRY, 2010, p. 35)". Contudo, em um regime totalitário, terror é "a própria essência da sua forma de governo (ARENDT, 2012, p. 477)", constituindo, portanto segundo Arendt:

A realização da lei do movimento. O seu principal objetivo é tornar possível à força da natureza ou da história propagar-se livremente por toda a humanidade sem o estorvo de qualquer menção humana espontânea. Como tal, o terror procura "estabilizar" os homens a fim de liberar as forças na natureza ou da história. (ARENDT, 2012, p. 618).

O mecanismo de controle denominado por Arendt de domínio total, tratava-se uma máquina fabricada para o poder e para o aniquilamento dos homens, sendo alcançado através da ideologia que implantava o terror. Tal forma de dominação, alcançava sua plenitude nos campos de concentração, que se tratavam do centro do sistema totalitário. Nestes locais, havia a perda da liberdade, e da individualidade do homem, além do mesmo perder "o seu modo particular de existir juridicamente (LAFER, 1988, p. 109)".

Para Arendt, os campos de concentração, visam não somente eliminar e maltratar seres humanos, visto que estes "servem à chocante experiência da eliminação, em condições cientificamente controladas, da própria espontaneidade como expressão da conduta humana (Arendt, 2012, p. 582)", sendo impossível não perder a própria identidade. Esta dominação absoluta do indivíduo, provoca assim "a 
destruição dos direitos de um homem, a morte de sua pessoa jurídica (ARENDNT, 2012, p. 598)".

O domínio totalitário não se contenta somente em restringir a liberdade do indivíduo (que é um direito fundamental do mesmo), estabelecendo limites para o seu exercício, visto que esta forma de controle visa deixar o indivíduo vazio dele mesmo, já este perde as características que o fazem um ser humano, tornando-o assim, uma marionete, um ser sem vontade própria nas mãos sistema.

Além de produzir um mundo de mortos-vivos, o totalitarismo trouxe algo inédito para a história da humanidade, impedindo a criação de mártires, não podendo haver nenhuma lembrança daqueles que caiam em desgraça porque "a dor e a recordação são proibidas (Arendt, 2012, p. 599)", para todos sem exceção. Na antiga União Soviética, seu líder Joseph Stálin, simplesmente apagava seus adversários que um dia foram seus aliados, conforme sua conveniência, das fotografias oficiais que iriam para os documentos e livros como se estes nunca houvessem existido, manipulando a história.

Não podendo ser lembrado após todos os suplícios realizados contra sua pessoa, e tendo seus direitos fundamentais suprimidos, o homem é completamente dominado, tendo aniquilado seu valor decorrente de sua humanidade, tornando-se supérfluo, isto é, alguém que sente não pertencer a este mundo, assim como uma pessoa pode sentir-se estranha morando em sua própria residência.

O homem supérfluo, perde sua singularidade que o torna um ser único, além do seu poder de escolha e decisão sobre si mesmo, podendo ser facilmente descartado, pois não faz diferença alguma em meio a uma multidão de pessoas condicionadas a agirem da mesma maneira. Para Arendt "não ter raízes significa não ter no mundo um lugar reconhecido e garantido pelos outros; ser supérfluo significa não pertencer ao mundo de forma alguma (ARENDT, 2012, p. 634)".

Portanto, perdendo seu modo particular de existência, o homem perde também sua personalidade jurídica e identidade, que eram destruídas no totalitarismo por intermédio de "torturas inteiramente inimagináveis, "dosadas de modo a não matar o corpo ou, pelo menos, não matá-lo imediatamente (ARENDT, 2012, P. 601)", completamente insanas.

Assim, espontaneidade do indivíduo era muita perigosa para o totalitarismo, posto que esta deixa as pessoas com comportamentos imprevisíveis, haja vista o potencial de criatividade armazenado na mente humana ser de enormes proporções, 
devendo por isto mesmo, ser arrasado, até deixar o homem com um vazio tão profundo que dificilmente possa encontrar-se preenchido novamente. O Estado totalitário, "não procura o domínio despótico dos homens, mas sim um sistema em que os homens sejam supérfluos (ARENDT, 2012, p. 605)", deixando o indivíduo sem capacidade de escolha, fazendo-o esquecer de que é um ser dotado de particularidades.

A destruição da individualidade do homem era fundamental para o totalitarismo, pois ele não podia ter atributos que poderiam fazê-lo uma pessoa com qualidades distintas de outros homens, devendo ser somente um ser sem ação em meio a uma massa subjugada pelo terror e pela ideologia. Esta destruição do homem em sua maneira de ser individual era importante para o sistema:

Porque destruir a individualidade é destruir a espontaneidade, a capacidade do homem de iniciar algo novo com os seus próprios recursos, algo que não possa ser explicado à base de reação ao ambiente e aos fatos. Morta a individualidade, nada resta senão terríveis marionetes, com rostos de homem [...] todas reagindo com perfeita previsibilidade mesmo quando marcham para a morte (ARENDT, 2012, p. 603).

O que torna a solidão tão insuportável no totalitarismo, é a perda do próprio eu, que pode realizar-se quando está a sós, mas cuja identidade só é confirmada pela companhia confiante e fidedigna dos meus iguais. Nessa situação, o homem perde a confiança em si mesmo como parceiro dos próprios pensamentos, e perde aquela confiança elementar no mundo que é necessária para que se possam ter quaisquer experiências. O eu e o mundo, a capacidade de pensar e de sentir, perdem-se ao mesmo tempo (ARENDT, 2012, p. 637).

Arendt, em sua visão sobre o totalitarismo, no tocante a natureza humana, acreditava que "é provável que a natureza da humanidade mude no totalitarismo, porque a liberdade de agir politicamente, que é um traço especificamente humano, é esmagada, permitindo que o totalitarismo se perpetue" (FRY, 2012, p. 37).

Pode-se afirmar, que fica evidente que a originalidade do homem não pode ser admitida em hipótese alguma no Estado Totalitário. Com a perda de sua identidade, a perda de seus direitos fundamentais e sua desumanização, o indivíduo torna-se, pois, um ser supérfluo, que sente não ter nenhum lugar no próprio mundo. Este vira alguém totalmente substituível e sem a menor importância para o sistema 
de dominação total que o afeta e condiciona, transformando a sua natureza, que é possuidora de múltiplas variáveis e possibilidades, em algo totalmente vazio e previsível.

Consequentemente, o homem que perdeu a sua humanidade, também não possui mais sua personalidade jurídica, visto que já não possui direito algum no qual possa se amparar, muito menos os direitos fundamentais, como garantidores de sua dignidade humana e bem-estar face ao Estado.

\section{CONSIDERAÇÕES FINAIS}

Verifica-se ao longo do presente trabalho, segundo a problemática levantada pela filósofa Hannah Arendt, que o totalitarismo controlava a vida do indivíduo de tal forma, que o privou de qualquer direito fundamental garantido ao ser humano.

Foi observado, ao longo do texto, que o totalitarismo deixou o indivíduo vazio como uma marionete a ser controlada conforme os interesses do Estado. Este sistema de governo retirou do homem não somente seus direitos, ou o exercício de sua liberdade, mas também retirou toda sua singularidade que é cruelmente suprimida, tendo em vista que esta é considerada subversiva. Daí constatar-se uma violação à personalidade jurídica do indivíduo, que é arrancado de toda a sua humanidade, usado como meio e não como um fim em si mesmo, posto que este não pode ser dotado de ações espontâneas que geram imprevisibilidade, tornandose assim um ser completamente indiferente e condicionado.

\section{REFERÊNCIAS}

AREDNT, Hannah. Origens do Totalitarismo. Trad. Roberto Raposo. - São Paulo: Companhia das Letras, 2012.

Assembleia Geral da ONU. "Declaração Universal dos Direitos Humanos". "Nações Unidas", 217 (III) A, 1948, Paris, http://www.un.org/en/universal-declaration-humanrights/. Acessa do em 6 de setembro de 2018.

BOBBIO, Norberto. A Era dos Direitos. Rio de Janeiro. Campus, 2004.

FERREIRA, Manoel Gonçalves. Direitos Humanos Fundamentais. - 11. ed. rev. e aum. - São Paulo: Saraiva, 2009. 
FRY, Karin A. Compreender Hannah Arednt. Trad. Paulo Ferreira Valério. Petrópolis, RJ: Vozes, 2010.

HUNT, Lynn. A invenção dos direitos humanos: uma história. São Paulo: Companhia das Letras, 2009.

LAFER, Celso. A reconstrução dos direitos humanos: um diálogo com o pensamento de Hannah Arendt. São Paulo: Companhia das Letras, 1988.

ROUSSEAU, Jean-Jacques. Os pensadores. São Paulo: Abril Cultural, 1977.

SOUZA, Paulo de Tarso Mendes. Apontamentos de Direito Constitucional. $-1^{\text {a }}$ ed. Brasília/Teresina: Fundação Astrogildo Pereira, 2009.

SARLET, Ingo Wolfgang. A Eficácia dos Direitos Fundamentais. Uma teoria geral dos Direitos Fundamentais na perspectiva constitucional. 10ํㅡㄹ ed. Porto Alegre: Livraria do Advogado Editora, 2010.

SILVA, José Afonso da. Curso de Direito Constitucional Positivo. 29a ed. São Paulo: Malheiros, 2007.

TRINDADE, J.D. de L. História Social dos direitos humanos. São Paulo: Fundação Petrópolis, 2002. 